\title{
Былое и думы. Ч. І. \\ Как в России ищут ответы на вызовы в смутные времена
}

В.И. КЛИСтОРИН, доктор экономических наук, Институт экономики и организации промышленного производства СО РАН, Новосибирск. E-mail: klistorin@ieie.ru

Рассмотрены экономические дискуссии в СССР в 1920-1980 гг., их тематика, основные позиции участников и результаты обсуждений. Показано, что в различные периоды уровень научных дискуссий и их влияние на развитие науки и экономической политики было неодинаковым. Особенно жаркие научные споры приходились на переломные периоды в экономической жизни страны, но их воздействие на выбор стратегии и институциональных реформ был минимальным. Экономические дискуссии в СССР всегда проходили в более или менее жестких идеологических рамках, хотя степень свободы научного творчества была разной. На уровне обсуждения сказывались ухудшение качества образования и деградация кадрового потенциала ученых-обществоведов. В то же время в отдельные периоды жизни страны наблюдалось восстановление качества экономических исследований.

Ключевые слова: экономические дискуссии, темпы роста, военный коммунизм, НЭП, послевоенные дискуссии, планирование хозяйственный расчет, экономико-математические модели, хозяйственный механизм

Любая интеллектуальная деятельность, любая наука, в том числе и экономическая, немыслима без дискуссий. Другое дело, каковы предмет дискуссии, методы и участники обсуждения, а самое главное - почему обсуждаются те или иные вопросы, кто их ставит, кто является арбитром и каковы итоги для науки и практики. В истории нашей страны было множество обсуждений различных экономических и социальных вопросов, и они имели самое разное отношение к действительным проблемам страны и собственно науки. Немаловажную роль в этих дискуссиях играют историческая память и различная интерпретация исторических событий.

Сталкиваясь с разными загадками, мы инстинктивно пытаемся свести новую задачу к тем, которые решались ранее, а при анализе ситуации, в которой оказалась страна, пытаемся найти в истории (в основном отечественной, но иногда и в мировой) нечто похожее. Нас не смущает, что каждая ситуация уникальна, а в истории нет и не может быть неизменно хороших или плохих решений, всеобщих схем и т. д., поскольку история делается 
людьми (причем не отдельными личностями, а массами), действующими под влиянием рациональных и иррациональных мотивов в рамках неполной и даже искаженной информации. При этом память играет с нами злую шутку: мы помним не всё и не так, как это было на самом деле. Фактически, мы всегда имеем дело с искаженной картиной происходившего, когда личные ощущения наслаиваются на мнения других людей, что-то почерпнуто из книг, фильмов, разговоров и т. д.

Экономисты, как и все прочие, считают, что люди разумны и обладают памятью. Но память бывает однобока, и обычная рядовая ситуация иногда воспринимается как беспрецедентная, а катастрофическая - как заурядная, «временные трудности». На помощь приходит наука, располагающая доступом к информационным массивам и инструментарию, позволяющему из этой информации извлекать содержательные и доказательные выводы.

Важную роль играет теория, т. е. та модель мира, которую мы используем для объяснения фактов и формирования наших представлений о будущем развитии ситуации и обоснования решений. И есть методология исследования, позволяющая сопоставить теоретическую модель с данными реальной действительности и оценить достоверность наших заключений и выводов. Все это и является обычно предметом научных дискуссий.

\section{Экономические дискуссии}

\section{в послереволюционный период}

До начала 1920-х экономические проблемы рассматривались во внутрипартийных дискуссиях как немаловажная часть революционной перестройки общества и при решении текущих вопросов. Об обсуждении актуальных проблем экономической теории и политики, а также методологии экономической науки вне партийных споров того периода нам ничего не известно.

Во внутрипартийных дискуссиях обсуждались вопросы возможности построения коммунизма в отдельно взятой стране, эффективности принудительного труда (милитаризации труда), отмирания государства в условиях диктатуры пролетариата и т. п. Арбитрами выступала узкая группа вождей, а истинной целью обсуждений была победа во внутрипартийной борьбе. Итоги дискуссий фиксировались в партийных документах и доводились до рядовых членов партии в виде директив и/или популярных изданий вроде «Азбуки коммунизма» Н. Бухарина и Е. Преображенского [1], часто отражавших не столько результаты анализа ситуации в рамках марксистской теории, сколько оправдание уже принятых решений. Жаркие споры, нашедшие свое документально подтверждение в материалах съездов ВКП (б), содержали множество эмоций, замешанных на политическом интересе.

Считалось, что партийные вожди, вооруженные единственно верным учением и диалектическим методом, могли выполнять любые функции - от командования фронтами до руководства наркоматами. Но особенно высоко ценились теоретическая работа и публицистика. Быстро выяснилось, что большевики имели очень поверхностное, а иногда и просто экзотическое представление о планировании, организации производства и распределения в масштабах народного хозяйства, функционировании банков и денежного обращения. Об этом говорит идея развития экономики страны как «единой фабрики» [2. С. 421-426] или представление о государственном банке как о «единой бухгалтерии» для всей экономики страны [1. С. 155-157].

Широко было распространено мнение о том, что конец капиталистически-товарного общества будет и концом политической экономии, поскольку «на место закономерностей стихийной жизни станет закономерность сознательных действий коллектива», а на месте политической экономии «останется одна лишь “экономическая география" - наука идиографического типа и нормативная наука “экономической политики”» [3].

Что касается академических дискуссий, то они возобновились только после перехода к НЭПу, когда оказалось, что «кавалерийская атака на капитализм» не удалась, и потребовалось привлечь «буржуазных» специалистов не только к технической работе, но и к содержательному обсуждению экономических и социальных проблем. К слову сказать, большинство ученых, участвовавших в дискуссиях 1920-х годов, были по убеждениям социалистами или близки к ним. Те же, кто придерживался других убеждений, иммигрировали, поменяли специальность или ушли в преподавание математики, географии, статистики, т. е. наук, более или менее далеких от экономической теории. 
Дискуссии периода НЭПа затрагивали самые разные стороны жизни.

Аграрная политика и стратегия развития кооперации. Первооткрыватель трудового крестьянского хозяйства А.В. Чаянов предлагал многоэтапный, растянутый по времени путь к сплошной кооперации, а его оппоненты настаивали на максимально быстром переходе к обобществлению крестьянских хозяйств, поскольку последние создавали базу для воспроизводства сельской буржуазии и капиталистических отношений вообще.

Природа и сущность планового хозяйства, цели и инструменты планирования в социалистической экономике Первая проблема состояла в том, как рассматривать план: как некий ориентир или директиву. Вторая - насколько радикальной может быть структурная перестройка экономики. Сторонники «генетического» подхода настаивали на постепенном изменении пропорций между секторами хозяйства, а приверженцы «телеологического» подхода были убеждены, что цель оправдывает средства. Первые отстаивали принцип баланса, вторые полагали, что соблюдение равновесия несущественно. Поскольку, как считали многие марксисты, капиталистическая индустриализация проходила за счет ограбления колоний и пролетаризации крестьянства, то и социалистическая индустриализация будет базироваться на перераспределении ресурсов из села и пролетаризации непролетарских элементов города и деревни.

Денежное обращение, кредит и регулирование цен. Г. Я. Сокольников утверждал и подтвердил на практике, что стабильность денежного обращения есть единственный путь к стабилизации и развитию народного хозяйства, а «эмиссия - опиум для народного хозяйства». Подобно С. Ю. Витте он быстро убедился в том, что денежная эмиссия и связанная с ней инфляция приводят не к росту, а к нехватке денег в экономике. Первоначальные иллюзии о том, что можно отменить все налоги и финансировать народное хозяйство исключительно за счет кредитов Госбанка, быстро рассеялись. Видимо, доводы Н. Кондратьева, Е. Слуцкого, А. Конюса и других сотрудников Конъюнктурного института при Наркомфине произвели впечатление на Г. Сокольникова. Но Е. Преображенский и другие «левые» экономисты считали, что повышенное налогообложение частников, «ножницы цен», денежная эмиссия и «социалистический протекционизм» дадут необходимые ресурсы для индустриализации [3. С. 430].

В.В. Новожилов показал в своих работах источники и механизмы инфляционных процессов, а также то, что товарный дефицит, спекуляция и коррупция есть прямое следствие регулирования цен ${ }^{1}$. Его оппоненты считали эти утверждения надуманными, а проблемы вполне преодолимыми при правильном выстраивании политики и верной расстановке кадров.

Налоговая политика. Должны ли налоги быть равномерными или допустима дифференциация налоговых ставок для отдельных категорий экономических агентов (государственных и частных предприятий, кулаков и середняков и т. д.)? Можно ли поднимать налоги в условиях замедления темпов роста экономики или предпочтительно снижать налоговый пресс? Как найти баланс между фискальной и регулирующей функциями налоговой системы? Из изложенного выше понятны позиции участников.

Уже во второй половине 1920-х годов темпы роста социалистической экономики замедлились, и началась дискуссия о темпах. Ее итог иронично подвел С. Г. Струмилин, сказав, что предпочитает стоять за высокие темпы, нежели сидеть - за низкие. Многие участники экономических дискуссий 1920-х годов были обвинены в правом уклоне и репрессированы. Другие такие как В.В. Новожилов, ушли в тень на долгие годы.

Постепенно менялись состав участников дискуссий и те рамки, в которых позволялось высказывать свое мнение. Историк А.Л. Сидоров в своих воспоминаниях писал: «Партийная жизнь в Институте была высоко развита, и в эпоху борьбы с оппозицией часто играла доминирующую роль в определении достоинств человека и в его будущей судьбе. Партийные связи с "верхами", а не успехи в науках определяли где-то лицо человека. До поры до времени это не сказывалось на тех, кто занимался историей и находил удовлетворение в педагогике или чисто научной сфере. Но постепенно получили ход люди карьеристские, мало интересовавшиеся наукой» [5. С. 451].

${ }^{1}$ Статьи В.В. Новожилова «Пределы инфляции» (1924 г.) и «Недостаток товаров» (1926 г.) были повторно опубликованы только в 1972 г. после смерти автора [4].

4 ЭКО. - 2016. - №2 
Значительный ущерб экономической науке и вклад в деградацию морали в научных коллективах внесла практика назначения на научные должности и перевод на преподавательскую работу в области общественных наук отставных чиновников, партийных функционеров и тому подобных лиц, нуждавшихся в синекуре, или для «кадрового укрепления ненадежных организаций». Какие уж тут дискуссии?! Разумеется, научные споры продолжались, например, об учебнике политической экономии. С итогами можно познакомиться в книге И. Сталина «Вопросы ленинизма» [6]

\section{Дискуссии в период оттепели}

Экономические дискуссии с негарантированным исходом возобновились только в конце 1950-х и в 1960-е годы. Можно выделить обсуждение товарного характера производства при социализме, суть которого была в том, что если при социализме производятся, обращаются и потребляются товары, то действуют и объективные законы товарного производства, а если нет - то можно научно обосновать и скалькулировать любые цены и пропорции. Научная общественность разделилась на «товарников» и «нетоварников». Хотя и те и другие считали, что при коммунизме закон цен утратит свое значение, но при социализме, как доказывали «товарники», когда еще не достигнуто товарное изобилие, действуют товарно-денежные отношения с остальным миром, и по ряду других причин товарный характер производства в СССР сохраняется.

Надо отметить, что еще в 1930-е годы отечественная экономическая наука разделилась на чистую теорию - политическую экономию социализма, и прикладную экономическую науку. которая занималась решением практических задач: обоснованием размещения производств и сроков строительства, расчетом потребности в ресурсах для реализации отдельных проектов, оптимизацией кооперативных связей предприятий и т. п. Очевидно, что специалисты, занятые подобной работой, во-первых, понимали важность ценовых показателей при обосновании эффективности проектов, а во-вторых, разрабатывали методы соизмерения затрат и результатов. И они составили ядро «товарников». Итогов дискуссии никто не подводил. Все остались при своем мнении, но представители школ прикладных исследований заявили о создании «конструктивной» экономической науки в противовес политэкономам и тем самым укрепили свои позиции в научном сообществе.

Уже в середине 1960-х годов обсуждались применимость и значение экономико-математических моделей в научных исследованиях. Суть дискуссии заключалась в ответе на вопрос: дает ли использование экономико-математических моделей новое знание о социально-экономических процессах или же только некоторые, весьма условные количественные характеристики этих процессов? Следует сказать, что к этому времени советские экономисты разными путями получили доступ к работам своих зарубежных коллег, для которых полезность использования математических моделей и методов в экономических исследованиях давно была бесспорной. Этому способствовало открытие некоторых фондов библиотек, общение с коллегами из социалистических стран, лучше знакомых с работами западных ученых, а потом и очное знакомство с последними. Постепенно расширялся перечень публикаций книг и статей зарубежных авторов.

Большую роль в восстановлении отечественной экономической науки сыграло издание многочисленных работ по истории экономической мысли и преподавание соответствующих курсов в университетах. Конечно, содержание этих курсов было основано на критике немарксистских теорий, но для того чтобы критиковать, следовало дать хотя бы самое общее представление о предмете критики. Кроме того, в основе подавляющего числа отечественных учебников лежали труды М.И. Туган-Барановского и ряд высококачественных работ других отечественных ученых [7-9].

В этой дискуссии речь, конечно же, шла не только и не столько о полезности того или иного инструментария при анализе и прогнозировании развития различных экономических ситуаций, сколько о выборе парадигмы экономической теории. Проницательный академик С.Г. Струмилин сразу понял, что под видом обоснования использования математических моделей в экономических исследованиях протаскивается «буржуазная» теория предельной полезности и предельной производительности, и не принимал активного участия в обсуждениях. Сторонники 
экономико-математического направления ссылались на авторитет К. Маркса, говорившего о том, что всякая наука становится таковой только после овладения математическим аппаратом, и указывали на другие преимущества математических моделей: четкость определения понятий и функциональных связей, использование только измеримых и количественно определяемых индикаторов, строгость выводов при принятии определенных гипотез и т. д.

Оппонентам трудно было возражать по существу, и они говорили о том, что жизнь гораздо богаче простых схем и детерминированных связей, а также о том, что использование формальной логики вместо диалектической убивает самое ценное в политической экономии.

Академики Л.В. Канторович и В.С. Немчинов были главной силой в отстаивании экономико-математического направления и организаторами научных подразделений этой специализации. Их активно поддержали А.Г. Аганбегян, В.В. Новожилов, В.Н. Богачев и многие другие. Создание научных институтов и лабораторий в Москве, Новосибирске, а потом и в других городах, присуждение единственной Ленинской премии по экономике Л.В.Канторовичу, В.С. Немчинову и В.В.Новожилову в 1965 г. фактически подвели итог дискуссии. Одновременно это резко расширило свободу научного творчества, поскольку идеологические работники и цензоры, как правило, не знали и не понимали математики, а аргумент, что выводы подтверждены расчетами на ЭВМ, был беспроигрышным. Поле исследований и возможность публикации результатов резко расширились.

Еще одним важным направлением ожесточенных споров был вопрос о пределах хозяйственного расчета социалистических предприятий. Фактически речь шла об использовании рыночных механизмов саморегулирования в социалистическом плановом хозяйстве. В 1960-е годы в европейских социалистических странах, a с 1965 г. - и в СССР начинаются реформы хозяйственного механизма, направленные на расширение самостоятельности предприятий. В теоретическом плане обсуждение шло вокруг проблемы совместимости локального и глобального оптимумов, а в практическом - в перераспределении полномочий, ответственности и, главное, ресурсов, между предприятиями и органами власти. Все шло к тому, что в СССР и других странах-членах СЭВ будет реализована модель, которую позднее использовали Китай, Вьетнам и некоторые другие страны, но чехословацкие события 1968 г. привели к отказу от реформы в СССР. Дискуссии по вопросам хозяйственной самостоятельности предприятий можно проследить по отечественным журналам, таким как «ЭКО», «Вопросы экономики», «Плановое хозяйство» и др. Публиковались как теоретические статьи, так и анализ деятельности отдельных предприятий и отраслей.

1970-е годы - это период экспериментов. Проводить широкомасштабные реформы власти не хотели, но что-то делать с неэффективной, способной развиваться только экстенсивно экономикой было необходимо. Анализу подобных экспериментов в регионах, на отдельных сельских и промышленных предприятиях, а также в пяти отраслях промышленности и строительства в 1979 г. посвящено множество публикаций, некоторые из них читаются с интересом и сегодня.

\section{Вместо заключения}

Данная статья представляет только первую часть обзора экономических дискуссий в нашей стране. Разумеется, она не претендует на полноту и всеохватность проблемы. Не названо большое число работ, не упомянуты многие видные участники обсуждений. Но даже краткая статья или ее фрагмент должны завершаться выводами.

Представленный анализ показывает, во-первых, что наиболее ожесточенные экономические дискуссии происходили в периоды системных кризисов в самой модели развития общества, которые характеризовались не только замедлением или падением производства и потребления, но и тем, что прежние механизмы управления народным хозяйством работали все хуже или не работали вовсе. Структура экономики признавалась неудовлетворительной, но изменить ее привычными методами и инструментами не представлялось возможным. Все это сопровождалось финансовым, бюджетным и управленческим кризисами. Так было накануне перехода к НЭПу и в период его угара, а далее - практически каждое послевоенное десятилетие.

Фактическая проблема, находящаяся в центре дискуссии, в большей или меньшей степени была завуалирована, замаскирована под относительно второстепенные вопросы. Всегда 
существовали запреты на обсуждение определенных научных проблем и вопросов экономической политики. Поэтому участники дискуссий использовали эзопов язык, и соответствующие тексты следует читать между строк, соотнося с историческим контекстом.

Экономические дискуссии оказывали крайне незначительное воздействие на решения органов власти. Последние скорее использовали риторику, терминологию и аргументы ученых и специалистов для обоснования тех решений, которые им казались наиболее удобными с тактической точки зрения. С другой стороны, многие участники научных дискуссий прекрасно понимали зигзаги политического курса и подстраивались под него.

Система централизованного планирования и распределения как главное преимущество социализма (в сравнении с капиталистической анархией) фактически не оставляла места для стратегического планирования. Множество авторов показали, что попытки реализации стратегических документов, начиная с программы КПСС и кончая комплексными программами научно-технического прогресса, заканчивались провалом. Экономика становилась все более неконкурентоспособной и неинновационной. Все это подталкивало к реформированию базовых институтов государства и общества, но писать об этом было нельзя.

Когда экономика страны приходит в неудовлетворительное состояние, власти и общество обращаются к экономической науке. При этом практически всегда следуют упреки в том, что экономисты недоработали, вовремя не предупредили о приближающихся проблемах, их наука излишне академична и оторвана от реальной жизни, некоторые ученые начинают говорить о кризисе в экономической науке и необходимости разработать новую парадигму. Кризисы в экономической науке, разумеется, бывали неоднократно, но эти упреки в условиях нашей страны огульно адресовать всем ученым несправедливо [10].

Сейчас Россия переживает системный кризис, как это неоднократно случалось за последние сто лет. Речь идет не просто о рецессии, падении производства и потребления. Такое периодически бывает и проходит почти само собой просто в силу того, что люди, как правило, стремятся улучшить свою жизнь, и, если это не делается за счет других, экономика растет естественным образом.
Другое дело, когда основные институты построены так, что перераспределительные механизмы работают более эффективно, нежели созидательные, и отнять и поделить - быстрее, проще и безопаснее, чем создавать новое богатство. Все это накладывается на потерю конкурентоспособности на внутреннем и внешних рынках. Это и называется системным кризисом, выход из которого осуществляется не просто расшивкой узких мест и залатыванием дыр, но перестройкой базовых институтов, без которой представляется невозможным изменение структуры экономики и приведение в соответствие факторов цены и производительности.

Кроме уже общепризнанной рецессии, в России имеют место финансовый (бюджетный, банковский и биржевой) кризис и кризис управления, выражающийся в создании все новых ведомств и перераспределении полномочий между ними, постоянных предложениях со всех сторон о создании, наряду с Правительством РФ, некоего органа стратегического управления и органов по координации ведомств. Но если Правительство не осуществляет эти функции, то возникает естественный вопрос о том, чем оно, собственно, занимается, и как принимаются решения на самом деле?

Все это сопровождается активными дискуссиями как о путях дальнейшего развития страны, так и вокруг методологии экономической науки. Когда экономика страны движется явно не в нужном направлении, и за что ни возьмись, изменить ситуацию невозможно, когда привычные методы и инструменты работают все хуже - дискуссии не просто обостряются. Позиции участников все более радикализируются, они все менее стесняются в выражениях, а аргументами в научных спорах все чаще становится обвинение оппонента в безграмотности, политической ангажированности и даже в предательстве Родины.

Собственно, для развития экономической науки, равно как и любой другой, дискуссии необходимы. Но в жизни нашей страны в XX веке неоднократно наблюдались дискуссии иного рода, а именно те, о которых говорилось выше.

\section{Литература}

1. Бухарин Н., Преображенский Е. Азбука коммунизма. Популярное объяснение программы Российской коммунистической партии 
большевиков / Звезда и свастика. Большевизм и русский фашизм. М.: TEPPA, 1994. - 317 c.

2. История экономических учений / Под ред. В. Автономова и др. М.: ИНФРА-М, 2002. - $784 \mathrm{c}$.

3. Бухарин Н. Политическая экономия рантье. - М.-Л., 1925. - С. 47. URL: http://www.esperanto.mv.ru/Marksismo/Bukharin/

4. Вопросы развития социалистической экономики. URL: http:/victor. sokirko.com/ecomomy/Zes3/1.1.htm

5. Воронкова С.В. Аркадий Лаврович Сидоров // Экономическая история. Ежегодник. - М.: Российская экономическая энциклопедия (РОССПЭН), 1999.

6. Сталин И. Вопросы ленинизма. Изд. 11-е. - М.: ОГИЗ, 1945. $611 \mathrm{c}$.

7. Туган-Барановский М. И. Очерки из новейшей истории политической экономии. - СПб.: Изд. журнала «Мир божий», 1903. X, 434 c. URL: http://dlib.rsl.ru/viewer/01003717545\#?page=1

8. Рубин И. И. Современные экономисты на Западе. - М. - Л.: Гос. издательство, 1927. - 324 с.

9. Блюмин И.Г. О современной буржуазной политической эконо9. Блюмин И.Г. О современной бурж

10. Клисторин В. И. О кризисе экономической науки в стране и мире // ЭКО. - 2009. - № 3. - С. 22-40.

Вторая часть статьи («Экономические дискуссии времен перестройки: невыученные уроки») будет опубликована в следующем номере.

\section{Читатель и журнал}

+1 \#17 Надежда Тимофеева 16.12.201521:48

- В богатом государстве богатые люди, или богатые люди образуют богатое государство? Похоже на вопрос про курицу и яйцо. Возможно, подход к благополучию у нас не с той стороны. Мы пытаемся обогатить государство, а надо обогатить людей, и они уже обогатят государство.

+1 \#2 Елизавета 15.12.201423:49

- ...Если приоритетны тактические выгоды, это повышает риск разбалансировки среды. В России, в основном, в приоритете именно тактические выгоды... Да, государство является активным участником конфликта интересов, иногда использует неформальные рычаги влияния. И это можно называть противоречивым процессом... А вообще, с такими «юными» законами помогут, наверное, только время и опыт.
0 \#16 Виолетта $16.12201522 \cdot 22$

- Наше правительство действительно обаятельное, или как минимум, хочет себя таковым показать. Воздействуя популистскими речами, оно вселяет веру простым людям. Хочется затронуть тему общественных социальных расходов. Громкими названиями «ласкают» наш слух новые проекты, как например, «Новое качество жизни» или приоритетные национальные проекты. Правительство обещает изменить жизнь, показывает суммы выделенных средств, официальные источники расхваливают положительные итоги. Но если посмотреть статистику, почитать критику, видно, что ПНП, по большей части, оказались провальными. По данным ВЦИОМ, 16\% россиян считают все ПНП пропагандистской акцией для отвлечения внимания людей от действий, направленных на ухудшение жизни населения. Национальные проекты никакого существенного результата не дадут, если не направить наше общество на "правильную” дорогу, решив хотя бы главные национальные проблемы: "дураки и дороги”, осмысленные в новом контексте.. Нравственное воспитание общества в рамках намеченного пути его развития!

0 \#1 Мария 24.11.201500:56

- На мой взгляд, нужно дать экономической деятельности в РФ больше свободы и допускать государственное вмешательство лишь в исключительных случаях. Иначе экономическая деятельность, подобно испуганному ребенку, будет прятаться за спину государства, или государство, подобно курице-наседке, будет губить самостоятельность своего чада.

+1 \#3 Васca 17.12.201402:01

- Как ни печально это признавать, но общество сейчас действительно совершенно оторвано от формирования важных экономических институтов. Взять хотя бы нашумевшие поправки в Налоговый кодекс, когда просьбы предпринимателей и сочувствующих пересмотреть поправки или вовсе отменить их были, на мой взгляд, самым грубым образом проигнорированы властью. Бизнес едва ли получает серьезную поддержку со стороны государства (если это, конечно, не «Роснефть»).

\section{+2 \#13 Скобеев Максим 16.12.201501:19}

- Следует признать, при глобализации конкурентные преимущества получают экономически сильные страны. В глобализации, как и в конкуренции, побеждает сильнейший. Одна из самых ключевых мировых проблем - это раскол общества, раскол населения по уровню дохода.

Глобализация способствует этому расколу, в том числе между странами. Поэтому от процессов глобализации сильные выигрывают еще больше, а слабые становятся еще слабее и беднее. 